\title{
Possible involvement of L-arginine-nitric oxide pathway in the antidepressant activity of Auraptene in mice
}

\author{
Hossein Amini-Khoei, Shakiba Nasiri Boroujeni, Forough Maghsoudi, Mohammad Rahimi-Madiseh, \\ Elham Bijad, Mohammadtaghi Moradi and Zahra Lorigooini* ${ }^{*}$
}

\begin{abstract}
Background: Depression is one of the most common mental illnesses worldwide. Nitric oxide (NO) is involved in the pathophysiology of depression. Auraptene (a coumarin derivative) has been shown to possess pharmacological effects on neurological diseases.

Purpose: The present study aimed to investigate the possible role of the NO pathway in Auraptene antidepressant effects in male mice.

Methods: Behavioral tests were used to assess depression-like behaviors. The mice received Auraptene at 10, 30, and $100 \mathrm{mg} / \mathrm{kg}$, the combination of the sub-effective (ineffective) dose of Auraptene $(10 \mathrm{mg} / \mathrm{kg}$ ) and L-NAME, and the combination of the effective dose of Auraptene $(30 \mathrm{mg} / \mathrm{kg})$ and L-arginine. Finally, OFT, TST, FST, brain, serum MDA level, antioxidant capacity, hippocampus, and serum NO level were measured.

Results: The data analysis showed that Auraptene $(30 \mathrm{mg} / \mathrm{kg})$ improved depression-like behaviors. Auraptene $(30 \mathrm{mg} / \mathrm{kg})$ also significantly reduced serum NO levels $(P<0.05)$ and significantly increased serum MDA $(10 \mathrm{mg} / \mathrm{kg}$, $P<0.05)$. Auraptene at $30 \mathrm{mg} / \mathrm{kg}$ also increased serum antioxidant capacity $(P<0.01)$. Co-administration of L-NAME and the sub-effective dose of Auraptene enhanced the effects of Auraptene. However, co-administration of the effective dose of Auraptene and L-arginine reduced the impacts of Auraptene.
\end{abstract}

Conclusions: The results showed that Auraptene causes antidepressant effects in a dose-dependent manner and acts as a prooxidant at $100 \mathrm{mg} / \mathrm{kg}$, and exacerbates oxidative stress. The antidepressant effects of this active molecule are exerted by reducing the NO level in the hippocampus and serum, increasing the antioxidant capacity, and reducing the MDA level in the serum.

Keywords: Depression, Nitric oxide, Auraptene, Coumarin derivative

\section{Introduction}

Depression is one of the most common psychiatric diseases with a prevalence of $15-25 \%$ and can cause a significant decline in patient performance in all occupational areas and social and family relationships [1]. Decreased

*Correspondence: zahralorigooini@gmail.com; lorigooini.z@skums.ac.ir Medical plants Research Center, Basic Health Sciences Institute,

Shahrekord University of Medical Sciences, Shahrekord, Iran function of neurotransmitters such as serotonin (5-HT), norepinephrine or noradrenaline (NA), and dopamine (DA) are some of the causes of depression [2].

Oxidative stress is an influential factor for various central nervous system disorders and can accelerate the aging process and lead to behaviors related to depression and anxiety. During oxidative stress, the production of free radicals exceeds the capacity of the body's antioxidant defense system, including enzymatic original author(s) and the source, provide a link to the Creative Commons licence, and indicate if changes were made. The images or other third party material in this article are included in the article's Creative Commons licence, unless indicated otherwise in a credit line to the material. If material is not included in the article's Creative Commons licence and your intended use is not permitted by statutory regulation or exceeds the permitted use, you will need to obtain permission directly from the copyright holder. To view a copy of this licence, visit http://creativecommons.org/licenses/by/4.0/. The Creative Commons Public Domain Dedication waiver (http://creativeco mmons.org/publicdomain/zero/1.0/) applies to the data made available in this article, unless otherwise stated in a credit line to the data. 
components (such as catalase) and non-enzymatic components (such as vitamin $\mathrm{C}$ and vitamin $\mathrm{E}$ ) to neutralize them. Consequently, free radicals cause cell damage and death by attacking various components, including nucleic acids, proteins, enzymes, and cell membrane lipids [3]. Serum malondialdehyde (MDA) level is one of the markers of lipid peroxidation and the critical indicator to evaluate oxidative stress. It has been explained that the total antioxidant capacity of serum is significantly reduced in people with major depressive disorder [4].

Nitric oxide (NO) is a free gas and messenger molecule that regulates the nervous and immune systems. Some studies have shown that $\mathrm{NO}$ is involved in depression and stress [5]. There are three different genetic isoforms of nitric oxide synthase [6] for NO production, including neuronal nitric oxide synthase (nNOS), endothelial nitric oxide synthase (eNOS), and induced nitric oxide synthase (iNOS). Several studies have shown the role of nNOS in the pathophysiology of depression, and antidepressants have been shown to reduce NO levels in the patient's serum [7-9].

Pharmacotherapy for depression can be associated with unwanted side effects such as anticholinergic and arrhythmic effects, which increasingly intensify the need to identify common drugs used to treat depression [10, 11]. Medicinal plants are a rich source of active secondary metabolites that widely draw researchers' attention [12].

Auraptene (7-geranyloxycoumarin) is a coumarin derivative isolated from the skin of some citrus and is the most abundant form of natural geranyloxycoumarin. Auraptene is found in many plants of the citrus genus, such as grapefruit and oranges [13], and has valuable medicinal properties, including anti-cancer, antibacterial, antifungal, anti-inflammatory, and antioxidant. Auraptene is also known to protect the nervous system [14-17].

Some coumarin compounds isolated from plant species exert inhibitory effects on monoamine oxidase. Monoamine oxidase A (MAO-A) selectively targets the catalysts of the neurotransmitters of serotonin and norepinephrine and is a pharmacological target in seeking out beneficial agents for the treatment of depression [18]. The evidence shows that coumarin compounds inhibit TNF- $\alpha$ or PGE2 secretion by affecting NFkB nucleus transport and inhibiting the phosphorylation of P38, JNK1/2, PKC kinases in LPS-stimulated macrophages and mononuclear cell lines. Moreover, research has shown that all coumarin compounds affect NO production by reducing the expression and activity of the iNOS gene and its protein, indicating the anti-inflammatory activity of coumarin compounds, e.g., Auraptene [19]. Coumarin compounds have been shown to exhibit anti-cancer properties by downregulating the PI3K/Akt and MEK/ERK pathways and increasing P-gp expression [20].

Therefore, this study aimed to investigate the antidepressant effects of Auraptene in male mice concerning the role of the NO pathway.

\section{Materials and methods Study design}

80 male NMRI mice were divided into eight groups $(\mathrm{n}=10)$ as follows [21-23]:

1. The group received normal saline.

2. Experimental group received Auraptene at the dose of $10 \mathrm{mg} / \mathrm{kg}$.

3. Experimental group received Auraptene at the dose of $30 \mathrm{mg} / \mathrm{kg}$.

4. Experimental group received Auraptene at the dose of $100 \mathrm{mg} / \mathrm{kg}$.

5. The group received nitric oxide synthetase [6] inhibitor (L-NAME) at $10 \mathrm{mg} / \mathrm{kg}$.

6. The group received $\mathrm{L}$-arginine ( $\mathrm{L}-\mathrm{arg})$ at $100 \mathrm{mg} / \mathrm{kg}$ $45 \mathrm{~min}$ before the test.

7. The group received a sub-effective dose of Auraptene plus L-NAME.

8. The group received an effective dose of Auraptene plus L-arg.

Auraptene was injected acutely and simultaneously with NO mediators intraperitoneally [21-23]. After injections, behavioral tests were performed, and after that, the brain and blood samples of mice under deep anesthesia with chloroform to minimize stress were taken. Then malondialdehyde content, antioxidant capacity, and NO in the brain and serum of mice were measured.

\section{Behavioral tests}

\section{Open field test (OFT)}

This test is used to evaluate the stress and emotional stability of rodents. The experimental groups were assessed on PND 45 using an open field apparatus, a box made of Plexiglas with dimensions of $60 \times 50 \times 40 \mathrm{~cm}$.

The box floor area was divided into 16 equal squares, and the movements of each mouse were monitored for $5 \mathrm{~min}$. This test is also used to assess anxiety based on vertical and horizontal directions and the amount of body scratching [24].

\section{Tail suspension test (TST)}

To do TST, each mouse was suspended from the edge of a rod $(50 \mathrm{~cm}$ above a tabletop) by adhesive Scotch tape located about $1 \mathrm{~cm}$ from the tip of the tail. Tail ascending was banned by passing the mouse's tail through a small plastic cylinder before the suspension. The period 
of immobility was recorded for $6 \mathrm{~min}$. Animals were considered immobile when they hung down passively and remained utterly motionless [25].

\section{Forced swimming test (FST)}

This test has been approved to investigate depression in rodents. According to the theory of helplessness of Martin Seligman, if the animal is exposed to constant stress and has no way out of it, it gradually loses hope of escaping and becomes immobile. The glass container $(25 \times 12 \times 15 \mathrm{~cm})$ was filled with $25^{\circ} \mathrm{C}$ water, and the animal was gently placed in the water from a height of $20 \mathrm{~cm}$. The discontinuation of movements of the mouse was considered immobility. The total duration of the FST is $6 \mathrm{~min}, 2 \mathrm{~min}$ for the animal's adaptation, and $4 \mathrm{~min}$ for measuring immobility. Increasing the immobility duration is considered depression, and its decrease is regarded as the effectiveness of antidepressant treatment [26].

\section{Biochemical tests}

\section{Measurement of the brain and plasma malondialdehyde levels}

A working solution was used for measuring the amount of malondialdehyde (MDA). It contained $0.5 \mathrm{~g}$ of thiobarbituric acid, $80 \mathrm{ml}$ acetic acid $20 \%$, whose $\mathrm{pH}$ reached 5.3 by adding sodium hydroxide $(\mathrm{NaOH})$ using a $\mathrm{pH}$ meter, and its final volume was increased to $100 \mathrm{ml}$ by the addition of $20 \%$ acetic acid. In the next step, $100 \mu \mathrm{l}$ of the sample, $100 \mu \mathrm{l}$ of $8.1 \%$ SDS, and $2.5 \mathrm{ml}$ of the working solution were mixed in a glass test tube and then the tubes in boiling water for one hour. The tubes were then cooled and centrifuged at $4000 \mathrm{rpm}$. Then the optical absorbance of the supernatant was recorded at $523 \mathrm{~nm}$ [27].

\section{Determination of serum and brain total antioxidant capacity}

The basis of the FRAP method is the ability of serum to reduce $\mathrm{Fe}+3$ ferric ions to ferrous $\mathrm{Fe}+2$ in the presence of an agent called TPTZ. In this method, the $\mathrm{Fe}+2$ reaction with the TPTZ reagent creates a blue $\mathrm{Fe}+2$-TPTZ complex with a maximum absorbance of $593 \mathrm{~nm}$. The serum's reducing power was measured by increasing the concentration of the above complex using spectrophotometry [28].

\section{Determining the nitric oxide level of the hippocampus}

To determine the NO level in the hippocampus, nitrite, as a stable product of $\mathrm{NO}$, was measured in different groups of animals after administration of different doses of Auraptene in the presence and absence of selective NOS inhibitor based on the Griess test. The basis of this reaction is the formation of the diazotization dye of a sulfonamide with the help of nitrite in an acidic medium and then its conjugation with an aromatic amine N-naphtyle ethylenediamine1 (NEDD) [22, 29].

\section{Data analysis}

Statistical analysis was performed using Prism software, and the results were expressed as Mean \pm SEM. Data were analyzed by one-way analysis of variance (ANOVA) and Tukey's post hoc test. The results were presented as mean plus SEM. $\mathrm{P}<0.05$ was considered a significance level.

\section{Results}

The number of horizontal movements in the OFT

As illustrated in Fig. 1, co-administration of Auraptene $(10 \mathrm{mg} / \mathrm{kg})$ and L-NAME significantly increased the number of horizontal movements in the OFT compared to the normal saline group $(\mathrm{P}<0.05)$, and the group received Auraptene at $10 \mathrm{mg} / \mathrm{kg}(\mathrm{P}<0.001)$. However, no significant difference was observed between the groups that received other doses of Auraptene in comparison with the normal group.

\section{The number of vertical movements in the OFT}

The one-way ANOVA and Tukey's post hoc test (Fig. 2) showed that administration of Auraptene at $30 \mathrm{mg} / \mathrm{kg}$ significantly increased the number of vertical movements in the OFT compared to the normal saline group $(\mathrm{P}<0.01)$. Moreover, co-administration of Auraptene $(10 \mathrm{mg} /$ $\mathrm{kg}$ ) and L-NAME significantly increased this movement compared to the normal saline group $(\mathrm{P}<0.01)$. Administration of $10 \mathrm{mg} / \mathrm{kg}$ Auraptene plus L-NAME

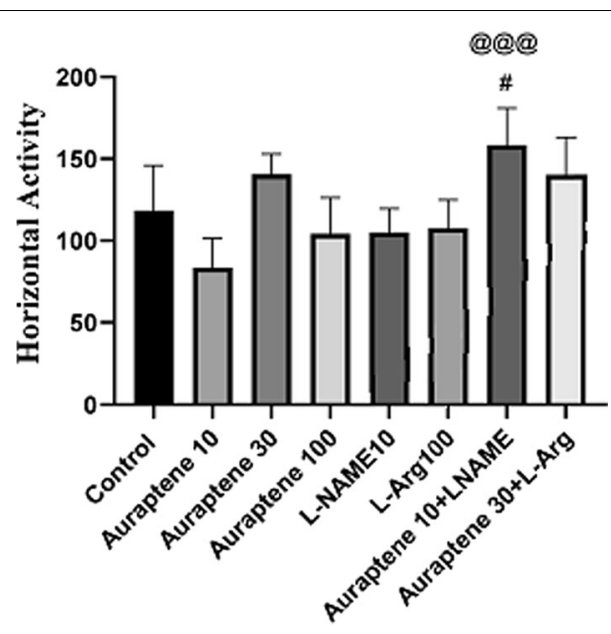

Fig. 1 The amount of horizontal movements in OFT in the experimental groups. Data were reported as Mean \pm SEM and analyzed using one-way ANOVA and Tukey post hoc test. ${ }^{\#} \mathrm{P}<0.05$ in compared to the normal group. ${ }^{@ @ P}<0.001$ in compared to the group that received Auraptene at a dose of $10 \mathrm{mg} / \mathrm{kg}$ 


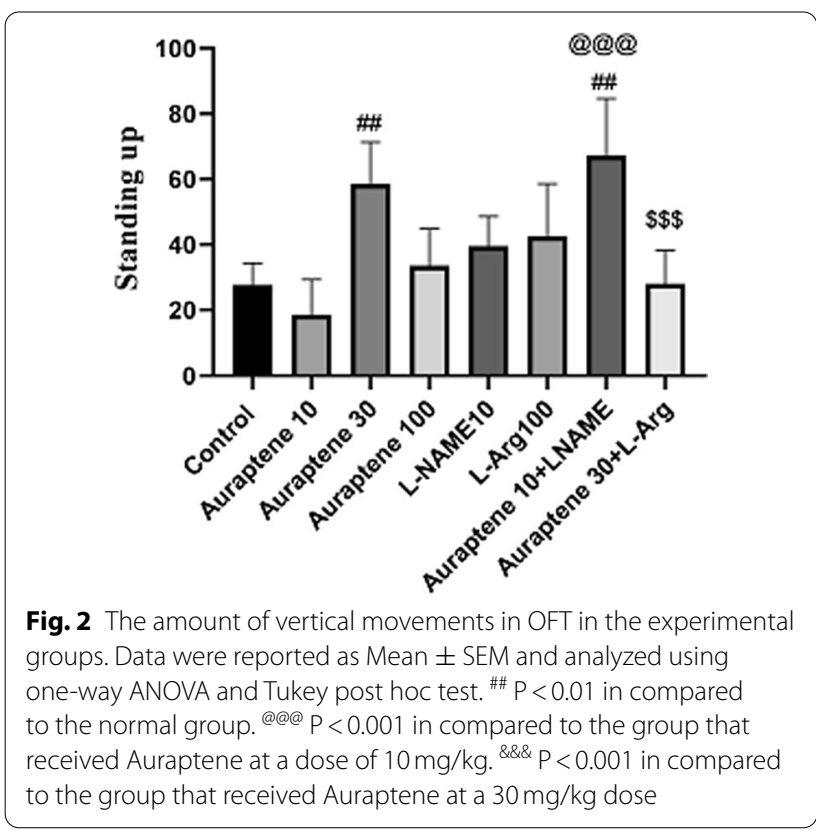

significantly increased the number of vertical movements compared to the group received $10 \mathrm{mg} / \mathrm{kg}$ Auraptene alone $(\mathrm{P}<0.001)$. Administration of Auraptene at a dose of $30 \mathrm{mg} / \mathrm{kg}$ plus L-Arg significantly reduced the number of vertical movements compared to the group that received $30 \mathrm{mg} / \mathrm{kg}$ Auraptene alone $(\mathrm{P}<0.001)$. However, the administration of Auraptene at the doses of 10 and $100 \mathrm{mg} / \mathrm{kg}$ and L-NAME and L-Arg alone did not have any significant difference in comparison with the normal saline group.

\section{The amount of scratching in the OFT}

The results of the amount of scratching in the OFT (Fig. 3) showed that the administration of Auraptene at doses of 30 and $100 \mathrm{mg} / \mathrm{kg}$ did not make any significant difference with the normal saline group. It should be noted that the administration of Auraptene at a dose of $10 \mathrm{mg} / \mathrm{kg}$ significantly reduced the amount of scratching in the OFT compared to the normal saline group $(\mathrm{P}<0.05)$. Also, administration of Auraptene at a dose of $10 \mathrm{mg} / \mathrm{kg}$ plus L-NAME significantly increased the amount of this behavior is compared to the group that received $10 \mathrm{mg} / \mathrm{kg}$ Auraptene alone $(\mathrm{P}<0.01)$.

\section{The duration of immobility in the TST}

As illustrated in Fig. 4, the Administration of Auraptene $(30 \mathrm{mg} / \mathrm{kg})$ significantly reduced the duration of immobility in the TST compared to the normal saline group $(\mathrm{P}<0.01)$. So the administration of Auraptene at $100 \mathrm{mg} /$ $\mathrm{kg}$ significantly increased the duration of immobility compared to the normal saline group $(\mathrm{P}<0.05)$. Also,

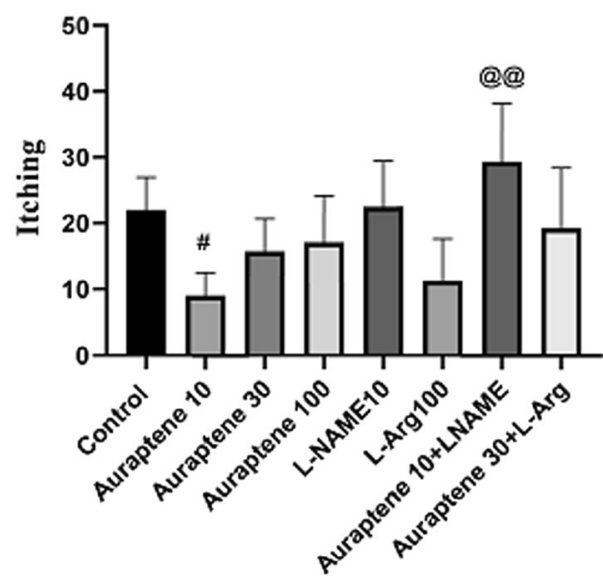

Fig. 3 The scratching rate in OFT in the experimental groups. Data were reported as Mean \pm SEM and analyzed using one-way ANOVA and Tukey post hoc test. ${ }^{\#} \mathrm{P}<0.05$ in compared to the normal group. $@ @ P<0.01$ in compared to the group that received Auraptene at a dose of $10 \mathrm{mg} / \mathrm{kg}$

administration of L-NAME $(10 \mathrm{mg} / \mathrm{kg})$ and administration of L-Arg $(100 \mathrm{mg} / \mathrm{kg})$ significantly reduced the duration of immobility compared to the normal saline group $(\mathrm{P}<0.001)$. Based on the results, we observed that auraptene at a dose of $10 \mathrm{mg} / \mathrm{kg}$ did not exert an antidepressant-like effect compared to the normal saline-received group; thus, this dose was selected as a sub-effective dose and co-administrated with L-NAME. Moreover, findings showed that auraptene at a $30 \mathrm{mg} / \mathrm{kg}$ dose possessed an antidepressant-like effect; thus, we selected this dose as an effective dose and co-administrated plus L-Arg. Co-administration of Auraptene $(30 \mathrm{mg} / \mathrm{kg})$ and L-Arg

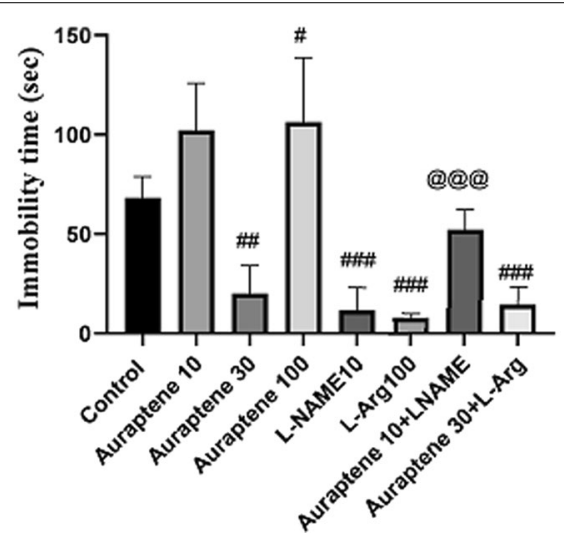

Fig. 4 The duration of immobility in TST in the experimental groups. Data were reported as Mean \pm SEM and analyzed using one-way ANOVA and Tukey post hoc test. ${ }^{\#} \mathrm{P}<0.05$, ${ }^{\#} \mathrm{P}<0.01$, and \#\#\# $\mathrm{P}<0.001$ in compared to the normal group. @@@ $\mathrm{P}<0.001$ in compared to the group that received Auraptene at a dose of $10 \mathrm{mg} / \mathrm{kg}$ 
significantly reduced immobility time compared to the normal saline group $(\mathrm{P}<0.001)$. Administration of Auraptene $(10 \mathrm{mg} / \mathrm{kg})$ plus L-NAME significantly reduced the duration of immobility in the TST in comparison to the group that received $10 \mathrm{mg} / \mathrm{kg}$ Auraptene alone $(\mathrm{P}<0.001)$.

\section{The duration of immobility in the FST}

The results of this study (Fig. 5) showed that the administration of Auraptene at $30 \mathrm{mg} / \mathrm{kg}$ significantly reduced the duration of immobility in the FST compared to the normal saline group $(\mathrm{P}<0.05)$. Moreover, administration of L-NAME $(10 \mathrm{mg} / \mathrm{kg})$ significantly reduced this time compared to the normal saline group $(\mathrm{P}<0.01)$. Coadministration of Auraptene $(10 \mathrm{mg} / \mathrm{kg})$ and L-NAME significantly reduced the duration of immobility compared to the group that received $10 \mathrm{mg} / \mathrm{kg}$ Auraptene alone $(\mathrm{P}<0.05)$.

\section{The serum and brain NO levels}

As illustrated in Fig. 6, administration of Auraptene at $30 \mathrm{mg} / \mathrm{kg}$ significantly reduced serum NO level compared to the normal saline group $(\mathrm{P}<0.05)$, while doses of 10 and $100 \mathrm{mg} / \mathrm{kg}$ did not produce any significant difference in comparison with the normal saline group. Injection of L-NAME at $10 \mathrm{mg} / \mathrm{kg}$ significantly reduced serum NO level compared to the normal saline group $(\mathrm{P}<0.001)$. Co-administration of Auraptene $(10 \mathrm{mg} / \mathrm{kg})$ and L-NAME significantly reduced the serum; NO level compared to the group that received Auraptene at $10 \mathrm{mg} /$ $\mathrm{kg}(\mathrm{P}<0.05)$.

According to the results (Fig. 7), administration of Auraptene at the doses of 10 and $100 \mathrm{mg} / \mathrm{kg}$ significantly

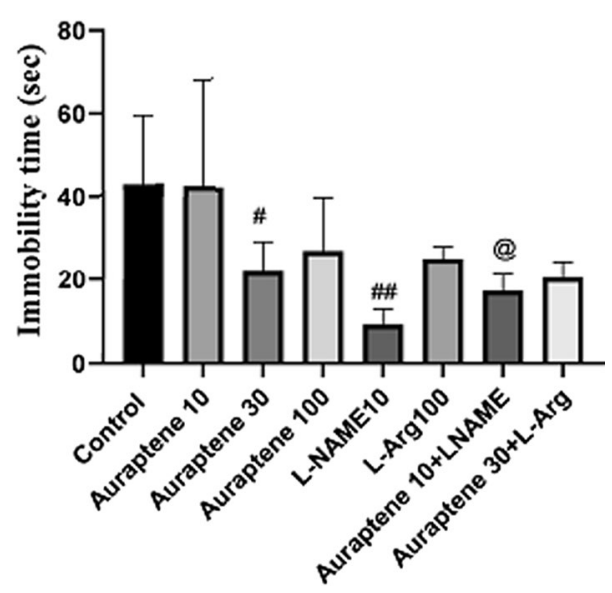

Fig. 5 The duration of immobility in FST in the experimental groups. Data were reported as Mean \pm SEM and analyzed using one-way ANOVA and Tukey post hoc test. ${ }^{\#} P<0.05$ and ${ }^{\#} P<0.01$ in comparison to the normal group. ${ }^{\circledR} \mathrm{P}<0.05$ in compared to the group that received Auraptene at a dose of $10 \mathrm{mg} / \mathrm{kg}$

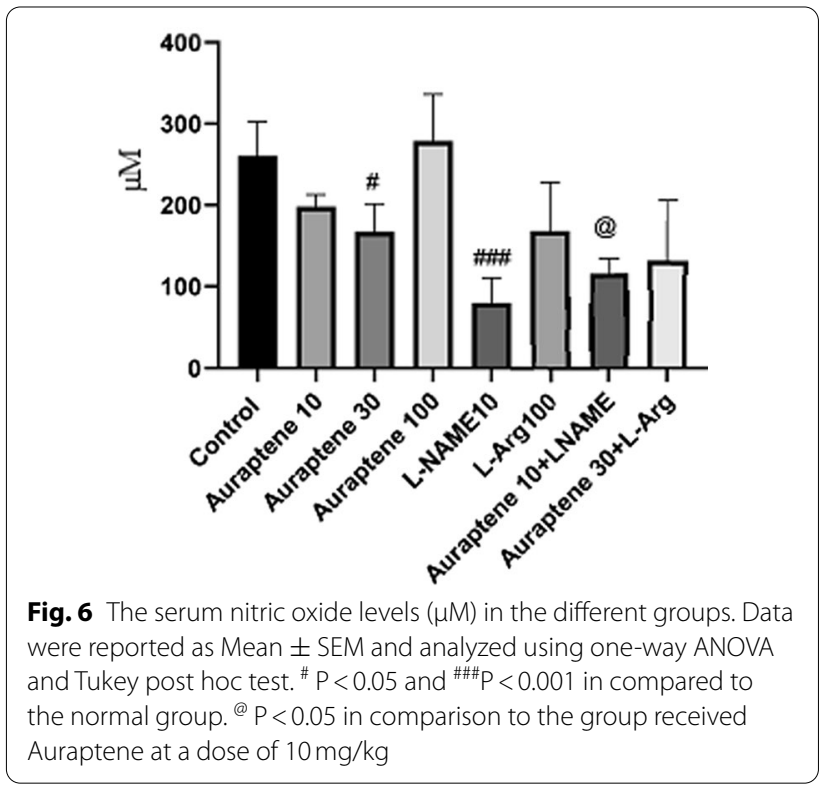

increased the brain NO level compared to the normal saline group $(\mathrm{P}<0.01$ and $\mathrm{P}<0.001)$. Besides, administration of L-Arg at $100 \mathrm{mg} / \mathrm{kg}$ significantly increased brain NO level compared to the normal saline group $(\mathrm{P}<0.001)$. Co-administration of Auraptene $(10 \mathrm{mg} / \mathrm{kg})$ and L-NAME significantly increased this level compared to the normal saline group $(\mathrm{P}<0.001)$.

\section{The serum and brain MDA levels}

Tukey's post hoc test (Fig. 8) showed that administration of Auraptene at $10 \mathrm{mg} / \mathrm{kg}$ significantly increased serum MDA levels compared to the normal saline group

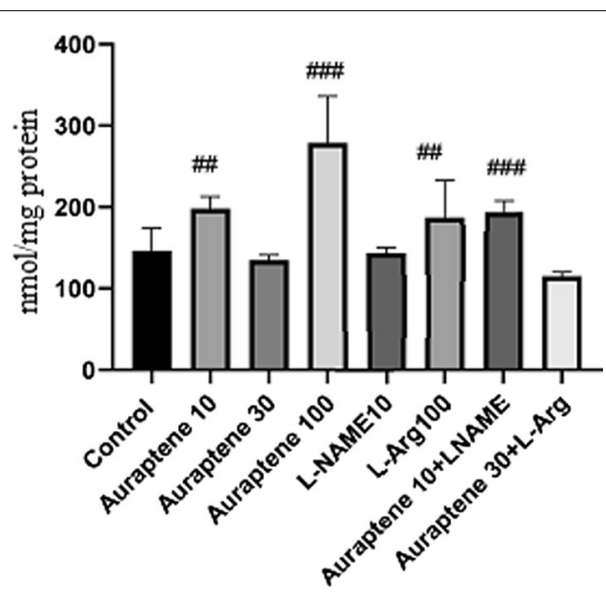

Fig. 7 The study groups showed brain nitric oxide content (nmol/ $\mathrm{mg}$ protein). Data were reported as Mean $\pm \mathrm{SEM}$ and analyzed using one-way ANOVA and Tukey post hoc test. ${ }^{\# \#} P<0.01$ and ${ }^{\# \#} P<0.001$ in compared to the normal group 


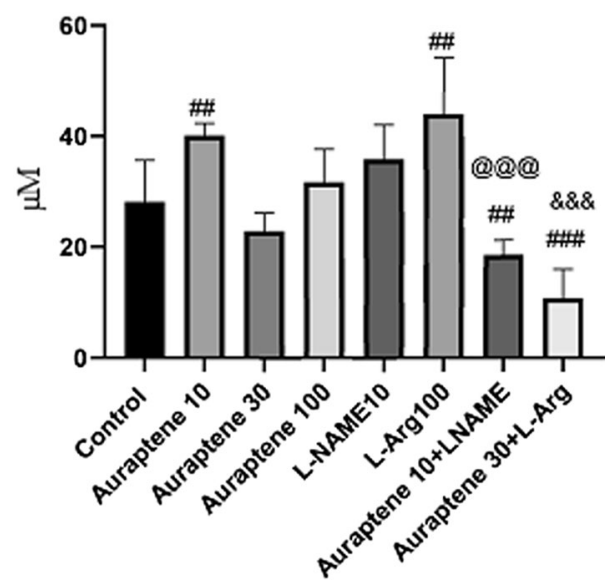

Fig. 8 Serum MDA levels $(\mu M)$ in the study groups. Data were reported as Mean \pm SEM and analyzed using one-way ANOVA and Tukey post hoc test. ${ }^{\#} P<0.01$ and ${ }^{\# \#} P<0.001$ in compared to the normal group. @@@ $\mathrm{P}<0.001$ in compared to the group that received Auraptene at a dose of $10 \mathrm{mg} / \mathrm{kg}$. \&\&\& $<0.001$ in compared to the group that received Auraptene at a $30 \mathrm{mg} / \mathrm{kg}$ dose

$(\mathrm{P}<0.05)$. Co-administration of Auraptene $(10 \mathrm{mg} / \mathrm{kg})$ and L-NAME significantly reduced serum MDA levels compared to the normal saline group and the group that received Auraptene alone $(\mathrm{P}<0.01$ and $\mathrm{P}<0.001$, respectively). Moreover, administration of Auraptene $(30 \mathrm{mg} /$ $\mathrm{kg}$ ) plus L-Arg significantly reduced serum MDA levels compared to the normal saline group and the group that received Auraptene alone $(\mathrm{P}<0.001)$.

The results (Fig. 9) showed that administration of Auraptene at 10,30 , and $100 \mathrm{mg} / \mathrm{kg}$ did not make any significant difference compared to the normal saline group. Nevertheless, the administration of L-Arg at $100 \mathrm{mg} / \mathrm{kg}$ significantly increased brain MDA levels compared to the normal saline group $(\mathrm{P}<0.01)$. Coadministration of Auraptene $(10 \mathrm{mg} / \mathrm{kg})$ and L-NAME significantly reduced brain MDA levels compared to the group that received Auraptene at $10 \mathrm{mg} / \mathrm{kg}$ alone $(\mathrm{P}<0.01)$.

\section{The serum and brain antioxidant capacity}

Administration of Auraptene at $10 \mathrm{mg} / \mathrm{kg}$ significantly reduced serum antioxidant capacity compared to the normal saline group $(\mathrm{P}<0.001$, Fig. 10). Auraptene at $30 \mathrm{mg} / \mathrm{kg}$ significantly reduced the serum capacity of antioxidants compared to the normal saline group $(\mathrm{P}<0.01)$. However, at the $100 \mathrm{mg} / \mathrm{kg}$ dose, it did not have any significant difference. Injection of L-NAME at $10 \mathrm{mg} /$ $\mathrm{kg}$ significantly reduced serum antioxidant capacity compared to the normal saline group $(\mathrm{P}<0.05)$. Co-administration of Auraptene $(30 \mathrm{mg} / \mathrm{kg}$ ) and L-Arg significantly increased serum antioxidant capacity compared to the normal saline group $(\mathrm{P}<0.001)$. Co-injection of Auraptene $(10 \mathrm{mg} / \mathrm{kg})$ and L-NAME significantly increased serum antioxidant level compared to the group that received Auraptene at $10 \mathrm{mg} / \mathrm{kg}$ alone $(\mathrm{P}<0.001)$.

Figure 11 illustrates no significant difference in the brain antioxidant capacity between the groups that received Auraptene at doses of 10, 30, and $100 \mathrm{mg} / \mathrm{kg}$ and the normal saline group. But the administration of Auraptene $(30 \mathrm{mg} / \mathrm{kg})$ plus L-Arg significantly increased brain antioxidant capacity compared to the normal saline group, and the group received $30 \mathrm{mg} / \mathrm{kg}$ of Auraptene

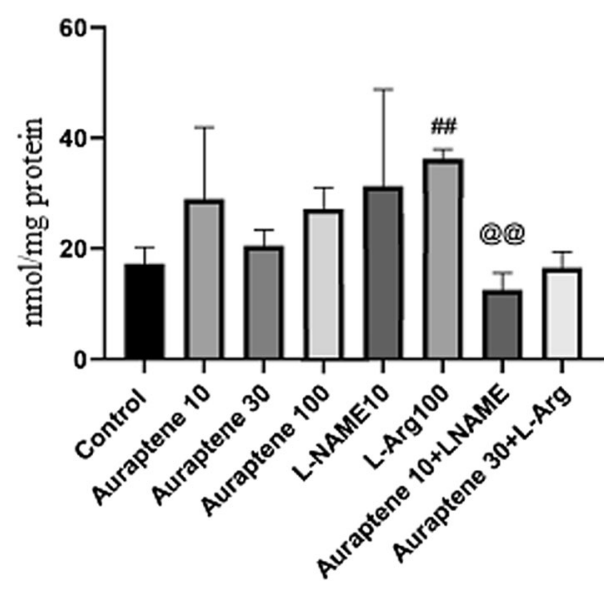

Fig. 9 Brain MDA levels ( $\mathrm{nmol} / \mathrm{mg}$ protein) in the study groups. Data were reported as Mean \pm SEM and analyzed using one-way ANOVA and Tukey post hoc test. ${ }^{\#} \mathrm{P}<0.01$ in compared to the normal group. $@ @ P<0.01$ in compared to the group that received Auraptene at a dose of $10 \mathrm{mg} / \mathrm{kg}$

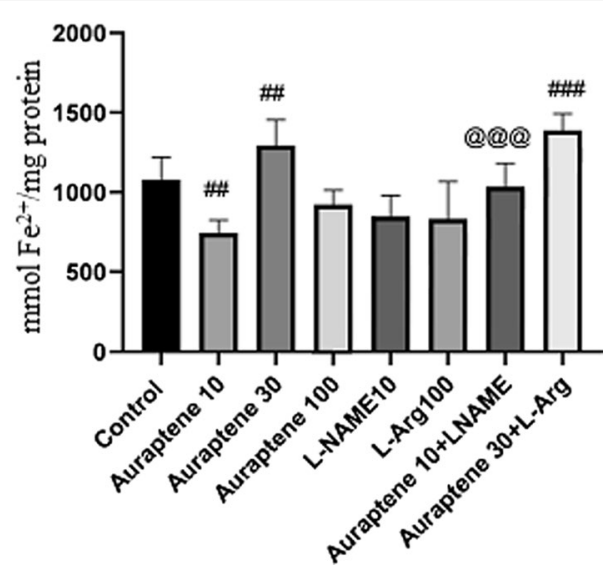

Fig. 10 Serum antioxidant capacity ( $\mathrm{mmol} \mathrm{Fe}^{2+} / \mathrm{mg}$ protein) in the experimental groups. Data were reported as Mean \pm SEM and analyzed using one-way ANOVA and Tukey post hoc test. ${ }^{*} P<0.05$, $\# P<0.01$, and \#\#\#<0.001 in compared to the normal group. @@@ $\mathrm{P}<0.001$ in compared to the group that received Auraptene at a dose of $10 \mathrm{mg} / \mathrm{kg}$ 


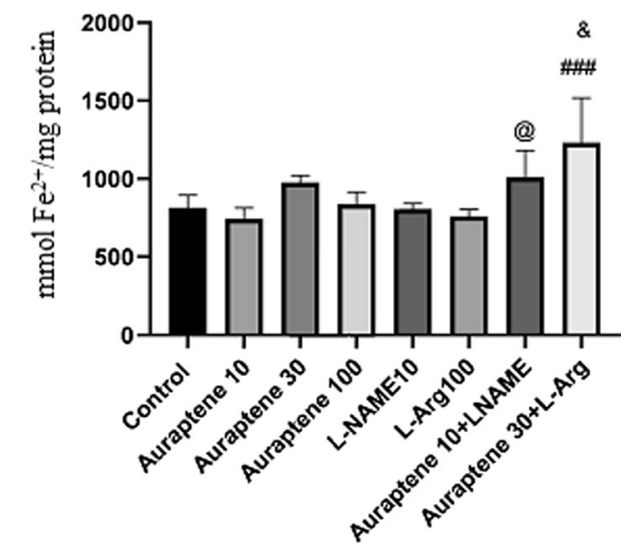

Fig. 11 Antioxidant capacity of the brain ( $\mathrm{mmol} \mathrm{Fe} \mathrm{e}^{2+} / \mathrm{mg}$ protein) in the experimental groups. Data were reported as Mean \pm SEM and analyzed using one-way ANOVA and Tukey post hoc test. ${ }^{\# \#}$ $\mathrm{P}<0.001$ in comparison to the normal group. ${ }^{@} \mathrm{P}<0.05$ in comparison to the group received Auraptene at a dose of $10 \mathrm{mg} / \mathrm{kg}$. ${ }^{\&} P<0.05$ in compared to the group that received Auraptene at a $30 \mathrm{mg} / \mathrm{kg}$ dose

$(\mathrm{P}<0.001$ and $\mathrm{P}<0.05$ respectively). Besides, co-administration of Auraptene $(10 \mathrm{mg} / \mathrm{kg})$ and L-NAME significantly increased the level of antioxidants in the brain is compared to the group that received $10 \mathrm{mg} / \mathrm{kg}$ Auraptene alone $(\mathrm{P}<0.05)$.

\section{Discussion}

This study aimed to investigate the antidepressant-like effect of Auraptene in male mice with regards to the NO pathway. Our results showed that Auraptene reduced the immobility duration in the FST and TST, indicating its antidepressant-like effect. We showed that Auraptene partially, at least, via an increase in antioxidant capacity and the reduction in the MDA and nitrite levels in the brain possessed its antidepressant-like effects.

It has been demonstrated that depression in rodents is associated with increased immobility time in the FST and TST [30]. Preclinical studies have shown that agents with antidepressant-like effects decreased the immobility time in the FST and TST [31]. This study observed that Auraptene reduced immobility time in the FST and TST, indicating its antidepressant-like effects.

Auraptene (7-geranyloxycoumarin) is a coumarin derivative found in many plants of the citrus genus, such as grapefruit and oranges [13]. Various pharmacological properties, including anti-cancer, antibacterial, antifungal, anti-inflammatory, and antioxidant effects, have been reported for Auraptene [15-17, 32]. A randomized, placebo-controlled, double-blind study in healthy volunteers showed that consumption of Auraptene as peels of citrus Kawachiensis (Kawachibankan) improved cognitive function [33]. Experimental studies have been determined that Auraptene has neuroprotective properties. In this regard, it has been shown that Auraptene, probably through attenuation of oxidative stress, exerted an anticonvulsant effect in pentylenetetrazol-induced chemical kindling in mice [34]. Furthermore, Auraptene mitigated nerve damage and enhanced memory following cerebral ischemia [35]. Our results showed that Auraptene possessed antioxidant properties that increased antioxidant capacity and reduced MDA and nitrite levels in the brain. These properties are contributed to possibly the antidepressant-like effect of Auraptene.

It has been determined that nitric oxide (NO) is involved in the pathophysiology of behavioral disorders like depression [36]. In this concept, previous studies showed that NO overproduction mitigated the antidepressant effect of antidepressants [37]. Moreover, inhibition of NO production potentiated the antidepressant effects of some agents $[38,39]$. In agreement with the abovementioned studies, our findings showed that NOS inhibitor (L-NAME) potentiated the antidepressantlike effect of a sub-effective dose of Auraptene. At the same time, L-arg (a NO precursor) attenuated the antidepressant-like effect of the effective dose of Auraptene. Therefore, possibly, NO is likely to contribute to the antidepressant-like development of Auraptene.

Clinical studies have demonstrated a direct association between concentrations of MDA in the plasma with the severity of depressive symptoms [40]. In this respect, researchers reported that major depressive disorder is associated with a decrease in antioxidant status and induction of oxidative and nitrosative pathways [6, $41,42]$. It has been well-determined that reduced antioxidant capacity is associated with increased MDA levels [43]. Ample evidence showed that some antidepressants exerted their effects by increasing the antioxidant capacity and decreasing MDA level [44, 45]. Our results showed that Auraptene significantly decreased MDA and increased antioxidant capacity. Furthermore, we observed that co-administration of L-NAME potentiated and L-arg mitigated the effect of Auraptene on the MDA level and antioxidant capacity.

This study indicates that Auraptene possessed an antidepressant-like effect by reducing NO and MDA levels and increasing antioxidant capacity. However, the mechanisms of action of Auraptene based on our study are not entirely determined, so; further studies are necessary to find exact mechanisms involved in the antidepressantlike effect of Auraptene.

\section{Conclusions}

Our results indicate that Auraptene exerted antidepressant-liker activity in mice by decreasing the $\mathrm{NO}$ and MDA levels and increasing antioxidant capacity. Findings 
showed that beneficial effects of Auraptene on depressive-like behaviors and oxidative stress markers are mediated via the NO pathway. Furthermore, we found that NOS inhibition potentiated while NO precursor mitigated the beneficial effects of Auraptene.

\section{Abbreviations}

NO: Nitric oxide; MDA: Malondialdehyde; L-NAME: L-Nitro arginine methyl ester; NA: Noradrenaline; DA: Dopamine; nNOS: Neuronal nitric oxide synthase; iNOS: Induced nitric oxide synthase; MAO-A: Monoamine oxidase A; OFT: Open field test; TST: Tail suspension test; FST: Forced swim test; $\mathrm{NaOH}$ : Sodium hydroxide.

\section{Acknowledgements}

The authors gratefully thank the Research and Technology Deputy of Shahrekord University of Medical Sciences for all supports provided.

\section{Authors' contributions}

ZLG and HAK contributed to the study's design, supervised the research and manuscript editing; FM and EB helped the supervision and preparation of the manuscript. EB, FM, MRM and SHNB performed the experiments and data collection and prepared manuscript drafting. MTM and ZLG revised the language and grammar of the manuscript. All authors read and approved the final manuscript.

\section{Funding}

This work was supported by grant No. 2782 from the Research Council of Shahrekord University of Medical Sciences.

\section{Availability of data and materials}

Data regarding the present study are available at Medical Plants Research Center, Shahrekord University of Medical Sciences.

\section{Declarations}

\section{Ethics approval and consent to participate}

All procedures were carried out following the regulations of the University and the Guide for the Care and Use of Laboratory Animals of National Institutes of Health (Ethical Code: IR.SKUMS.REC.1397.70) and Guide for the Care and Use of Laboratory Animals (8th edition, National Academies Press). Full efforts were made to reduce animals' use and advance their welfare.

\section{Consent for publication}

All authors are agreed to publish this manuscript.

\section{Competing interests}

The authors have no conflicts of interest to declare regarding the study described in this article and the preparation.

Received: 6 January 2021 Accepted: 8 February 2022

Published online: 14 February 2022

\section{References}

1. Kandel ER, Schwartz JH, Jessell TM, Jessell MBT, Siegelbaum S, et al. Principles of neural science. New York: McGraw-hill; 2000

2. Nutt DJ. Relationship of neurotransmitters to the symptoms of major depressive disorder. J Clin Psychiatry. 2008;69:4-7.

3. Pandya CD, Howell KR, Pillai A. Antioxidants as potential therapeutics for neuropsychiatric disorders. Prog Neuropsychopharmacol Biol Psychiatry. 2013;46:214-23.

4. Sarandol A, Sarandol E, Eker SS, Erdinc S, Vatansever E, Kirli S. Major depressive disorder is accompanied with oxidative stress: short-term antidepressant treatment does not alter oxidative-antioxidative systems. Hum Psychopharmacol. 2007;22(2):67-73.
5. van Amsterdam JG, Opperhuizen A. Nitric oxide and biopterin in depression and stress. Psychiatry Res. 1999;85(1):33-8.

6. Manosso LM, Camargo A, Dafre AL, Rodrigues ALS. Vitamin E for the management of major depressive disorder: possible role of the antiinflammatory and antioxidant systems. Nutr Neurosci. 2020;1:1-15.

7. Dhir A, Kulkarni S. Involvement of nitric oxide (NO) signaling pathway in the antidepressant action of bupropion, a dopamine reuptake inhibitor. Eur J Pharmacol. 2007;568(1-3):177-85.

8. Heiberg IL, Wegener G, Rosenberg R. Reduction of cGMP and nitric oxide has antidepressant-like effects in the forced swimming test in rats. Behav Brain Res. 2002;134(1-2):479-84.

9. Joca SRL, Guimarães FS. Inhibition of neuronal nitric oxide synthase in the rat hippocampus induces antidepressant-like effects. Psychopharmacology. 2006;185(3):298-305.

10. Baldwin D, Woods R, Lawson R, Taylor D. Efficacy of drug treatments for generalised anxiety disorder: systematic review and meta-analysis. BMJ. 2011;342:d1199.

11. Sirois FM, Gick ML. An investigation of the health beliefs and motivations of complementary medicine clients. Soc Sci Med. 2002:55(6):1025-37.

12. Ho Y-J, Wang C-F, Hsu W-Y, Tseng T, Hsu C-C, Kao M-D, et al. Psychoimmunological effects of dioscorea in ovariectomized rats: role of anxiety level. Ann Gen Psychiatry. 2007;6(1):21.

13. Curini M, Cravotto G, Epifano F, Giannone G. Chemistry and biological activity of natural and synthetic prenyloxycoumarins. Curr Med Chem. 2006;13(2):199-222.

14. Abdel-Latif NA. Synthesis and antidepressant activity of some new coumarin derivatives. Sci Pharm. 2005;73(4):193-216.

15. Curini M, Epifano F, Messina F, Genovese S. Antibacterial properties of auraptene and oxyprenylated naturally occurring benzoic and cinnamic acids. Bol Latinoam Caribe Plant Med Aromat. 2012;11(1):74-6.

16. Genovese S, Epifano F. Auraptene: a natural biologically active compound with multiple targets. Curr Drug Targets. 2011;12(3):381-6.

17. Soltani F, Mosaffa F, Iranshahi M, Karimi G, Malekaneh M, Haghighi F, et al. Auraptene from Ferula szowitsiana protects human peripheral lymphocytes against oxidative stress. Phytother Res. 2010;24(1):85-9.

18. Vergel NE, López JL, Orallo F, Viña D, Buitrago DM, del Olmo E, et al. Antidepressant-like profile and MAO-A inhibitory activity of 4-propyl2H-benzo [h]-chromen-2-one. Life Sci. 2010;86(21-22):819-24.

19. Stefani HA, Gueogjan K, Manarin F, Farsky SH, Zukerman-Schpector J, Caracelli I, et al. Synthesis, biological evaluation and molecular docking studies of 3-(triazolyl)-coumarin derivatives: effect on inducible nitric oxide synthase. Eur J Med Chem. 2012;58:117-27.

20. Guo Y, Wang Y, Li H, Wang K, Wan Q, Li J, et al. Novel nitric oxide donors of phenylsulfonylfuroxan and 3-benzyl coumarin derivatives as potent antitumor agents. ACS Med Chem Lett. 2018;9(5):502-6.

21. Haj-Mirzaian A, Amiri S, Kordjazy N, Momeny M, Razmi A, Rahimi-Balaei $M$, et al. Lithium attenuated the depressant and anxiogenic effect of juvenile social stress through mitigating the negative impact of interlukin-1 $\beta$ and nitric oxide on hypothalamic-pituitary-adrenal axis function. Neuroscience. 2016;315:271-85.

22. Haj-Mirzaian A, Kordjazy N, Amiri S, Haj-Mirzaian A, Amini-Khoei $\mathrm{H}$, Ostadhadi $\mathrm{S}$, et al. Involvement of nitric oxide-cyclic guanosine monophosphate pathway in the antidepressant-like effect of tropisetron and ondansetron in mice forced swimming test and tail suspension test. Eur J Pharmacol. 2016;780:71-81.

23. Razavi BM, Arasteh E, Imenshahidi M, Iranshahi M. Antihypertensive effect of auraptene, a monoterpene coumarin from the genus Citrus, upon chronic administration. Iran J Basic Med Sci. 2015;18(2):153.

24. Haj-Mirzaian A, Nikbakhsh R, Ramezanzadeh K, Rezaee M, Amini-Khoei H, Haj-Mirzaian A, Ghesmati M, Afshari K, Haddadi NS, Dehpour AR. Involvement of opioid system in behavioral despair induced by social isolation stress in mice. 109: Biomedicine \& Pharmacotherapy; 2019. pp. 938-44.

25. Sun L-Q. Information on research and application of ginseng, the king of traditional and herbal medicines. Asian J Drug Metabolism Pharmacokinet. 2004;4(4):261-84

26. Haj-Mirzaian A, Amiri S, Amini-Khoei H, Haj-Mirzaian A, Hashemiaghdam A, Ramezanzadeh K, Ghesmati M, Afshari K, Dehpour AR. Involvement of NO/NMDA-R pathway in the behavioral despair induced by amphetamine withdrawal. Brain Res Bull. 2018:139:81-90. 
27. Kuloglu M, Atmaca M, Tezcan E, Ustundag B, Bulut S. Antioxidant enzyme and malondialdehyde levels in patients with panic disorder. Neuropsychobiology. 2002;46(4):186-9.

28. Benzie IF, Strain J. [2] Ferric reducing/antioxidant power assay: direct measure of total antioxidant activity of biological fluids and modified version for simultaneous measurement of total antioxidant power and ascorbic acid concentration. Methods in enzymology. 299: Elsevier; 1999. pp. 15-27.

29. Granger DL, Taintor RR, Boockvar KS, Hibbs JB Jr. Measurement of nitrate and nitrite in biological samples using nitrate reductase and Griess reaction. Methods in enzymology. 268: Elsevier; 1996. pp. 142-51.

30. Vadnie CA, DePoy LM, McClung CA. Measuring the Effects of Circadian Rhythm-Related Manipulations on Depression-Like Behavior in Rodents: Forced Swim and Tail Suspension Tests. Circadian Clocks: Springer; 2021. pp. 69-78.

31. Deyama S, Kaneda K. The duration of the antidepressant-like effects of a single infusion of brain-derived neurotrophic factor into the medial prefrontal cortex in mice. Behav Brain Res. 2020;394:112844.

32. Bibak B, Shakeri F, Barreto GE, Keshavarzi Z, Sathyapalan T, Sahebkar A. A review of the pharmacological and therapeutic effects of auraptene. BioFactors. 2019;45(6):867-79.

33. Igase M, Okada Y, Ochi M, Igase K, Ochi H, Okuyama S, et al. Auraptene in the peels of Citrus Kawachiensis (Kawachibankan) contributes to the preservation of cognitive function: A randomized, placebo-controlled, double-blind study in healthy volunteers. J Prev Alzheimer's disease. 2018;5(3):197-201.

34. Etemad L, Zamani M, Iranshahi M, Roohbakhsh $A$. The protective effect of auraptene against oxidative stress and pentylenetetrazol-induced chemical kindling in mice. Iran J Pharm Res. 2019;18(3):1395.

35. Ghanbarabadi M, Iranshahi M, Amoueian S, Mehri S, Motamedshariaty VS, Mohajeri SA. Neuroprotective and memory enhancing effects of auraptene in a rat model of vascular dementia: experimental study and histopathological evaluation. Neurosci Lett. 2016;623:13-21.

36. Lim DW, Kim M, Yoon M, Lee J, Lee C, Um MY. 1, 3-Dicaffeoylquinic acid as an active compound of Arctium lappa root extract ameliorates depressive-like behavior by regulating hippocampal nitric oxide synthesis in ovariectomized mice. Antioxidants. 2021;10(8):1281.

37. Rossetti AC, Paladini MS, Riva MA, Molteni R. Oxidation-reduction mechanisms in psychiatric disorders: A novel target for pharmacological intervention. Pharmacol Ther. 2020;210:107520.

38. Hashimoto K. Rapid-acting antidepressant ketamine, its metabolites and other candidates: a historical overview and future perspective. $J$ Neuropsych Clin Neurosci. 2019;73(10):613-27.

39. Borowicz-Reutt KK, Banach M. Acute and chronic treatment with moclobemide, a reversible MAO-inhibitor, potentiates the antielectroshock activity of conventional antiepileptic drugs in mice. Pharmacol Biochem Behav. 2021;201:173110.

40. Talarowska M, Gałecki P, Maes M, Gardner A, Chamielec M, Orzechowska A, et al. Malondialdehyde plasma concentration correlates with declarative and working memory in patients with recurrent depressive disorder. Mol Biol Rep. 2012;39(5):5359-66.

41. Duarte-Silva E, Maes M, Macedo D, Savino W, Peixoto CA. Shared neuroimmune and oxidative pathways underpinning Chagas disease and major depressive disorder. Transl Psychiatry. 2020;10(1):1-10.

42. Vasupanrajit A, Jirakran K, Tunvirachaisakul C, Maes M. Suicide attempts are associated with activated immune-inflammatory, nitro-oxidative, and neurotoxic pathways: a systematic review and meta-analysis. J Affect Disorders. 2021;295:80-92.

43. Maes M, Galecki P, Chang YS, Berk M. A review on the oxidative and nitrosative stress (O\&NS) pathways in major depression and their possible contribution to the (neuro) degenerative processes in that illness. Prog Neuropsychopharmacol Biol Psychiatry. 2011;35(3):676-92.

44. Nasiri-Boroujeni S, Rahimi-Madiseh M, Lorigooini Z, Piroti K, RafieianKoupaei M, Amini-Khoei H. NMDA receptor mediates the anticonvulsant effect of hydroalcoholic extract of Artemisia persica in PTZ-Induced Seizure in Mice. Evid Based Compl Altern Med. 2021;2021:6422451.

45. Nouri A, Hashemzadeh F, Soltani A, Saghaei E, Amini-Khoei H. Progesterone exerts antidepressant-like effect in a mouse model of maternal separation stress through mitigation of neuroinflammatory response and oxidative stress. Pharm Biol. 2020;58(1):64-71.

\section{Publisher's Note}

Springer Nature remains neutral with regard to jurisdictional claims in published maps and institutional affiliations.
Ready to submit your research? Choose BMC and benefit from:

- fast, convenient online submission

- thorough peer review by experienced researchers in your field

- rapid publication on acceptance

- support for research data, including large and complex data types

- gold Open Access which fosters wider collaboration and increased citations

- maximum visibility for your research: over $100 \mathrm{M}$ website views per year

At BMC, research is always in progress.

Learn more biomedcentral.com/submissions 